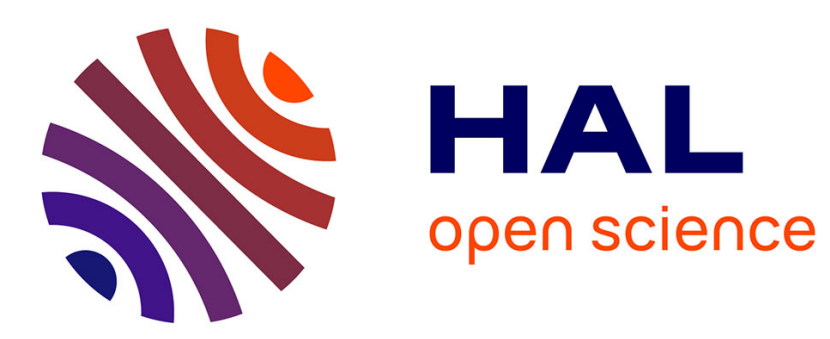

\title{
Modelling radiative and energy balance on heterogeneous areas from remotely-sensed radiances
}

F.A. Bouguerzaz, Albert Olioso, M. Raffy

\section{To cite this version:}

F.A. Bouguerzaz, Albert Olioso, M. Raffy. Modelling radiative and energy balance on heterogeneous areas from remotely-sensed radiances. Canadian Journal of Remote Sensing, 1999, 25 (4), pp.412-424. hal-02697568

\section{HAL Id: hal-02697568 \\ https://hal.inrae.fr/hal-02697568}

Submitted on 1 Jun 2020

HAL is a multi-disciplinary open access archive for the deposit and dissemination of scientific research documents, whether they are published or not. The documents may come from teaching and research institutions in France or abroad, or from public or private research centers.
L'archive ouverte pluridisciplinaire HAL, est destinée au dépôt et à la diffusion de documents scientifiques de niveau recherche, publiés ou non, émanant des établissements d'enseignement et de recherche français ou étrangers, des laboratoires publics ou privés. 


\section{Modelling Radiative and Energy Balance on Heterogeneous Areas from Remotely-Sensed Radiances}

\section{by F.A. Bouguerzaz $\bullet$ A. Olioso $・$ M. Raffy}

\section{$R E ́ S U M E$}

L'évapotranspiration (LE), la photosynthèse $\left(A_{c}\right)$, l'albédo et la fraction absorbée du rayonnement photosynthétiquement actif (fAPAR) sont des variables constituant une importante source d'information pour l'analyse et la gestion des écosystèmes agricoles et naturels. Les modèles de Transferts Sol-Végétation-Atmosphère (SVAT) permettent actuellement de quantifier ces variables. Les modèles SVAT incluent des paramétrisations détaillées des échanges d'énergie, d'eau et de quantité de mouvement entre les surfaces terrestres et l'atmosphère. Ces modèles ont en général été établis pour des surfaces «homogènes», i.e. pour lesquelles les caractéristiques des paysages sont considérées homogènes. Les paramètres de ces modèles décrivent la physiologie et la géométrie des plantes ; ils sont mesurables à l'échelle d'un milieu homogène, mais ne permettent pas la description des variables intéressantes sur des surfaces hétérogènes. À plus large échelle, comme les modèles SVAT ne sont pas linéaires, l'hétérogénéité des paysages peut entraîner des erreurs substantielles dans l'estimation de ces variables. Ceci est une raison majeure des difficultés d'utilisation de ces modèles avec des données satellitaires (luminances).

Sur la base de résultats théoriques récents, nous définissons un nouveau modèle adapté aux pixels hétérogènes, appelé modèle «spatialisé ». Nous considérons des pixels constitués de divers couverts homogènes pour lesquels la connaissance des paramètres individuels permet le calcul des variables précédentes. Le modèle résultant permet de dériver ces variables à partir des mesures de luminances à l'échelle des pixels. L'analyse de ces résultats sur des zones hétérogènes, en utilisant des simulations locales, montre une bonne précision du modèle spatialisé pour quantifier $L E, A_{c}$, albédo et fAPAR. Ces résultats démontrent également l'importance des changements d'échelle et ouvrent la voie à diverses applications.

Mots-clefs : Télédétection, Hétérogénéité, Flux de chaleur latente, Photosynthèse, Albédo, fAPAR.

\section{SUMMARY}

Evapotranspiration ( $L E)$, photosynthesis $\left(A_{C}\right)$, albedo and the fraction of absorbed photosynthetically active radiation $(f A P A R)$ constitute an important source of information for the analysis and management of agricultural and natural ecosystems. Soil-Vegetation-Atmosphere Transfer (SVAT) models currently allow quantification of these variables. SVAT models are highly parameterized abstractions of energy, moisture, and momentum exchanges between the land and the atmosphere. These models have usually been designed for homogeneous surfaces, where landscapes are considered as having homogeneous surface characteristics. Then, the models depend on various parameters noted $(p)$ of the physiology and geometry of plants, that are only measurable at local scale and do not allow for the description of the variables for heterogeneous areas. At a larger scale, since SVAT models are non-linear, landscape heterogeneity can lead to substantial errors in the estimation of the variables of interest. This is the key reason for the difficulty in using these models with satellite data (radiances).

On the basis of recent theoretical results, we define a new model adapted to heterogeneous pixels, called the spatialized model. Namely, we consider a pixel region covered with various homogeneous cover types for which the knowledge of the individual parameters ( $p 1 \ldots p k$ ) allows the computation of the aforementioned variables.

The resulting model yields these variables from global radiances at the pixel scale. The comparison of the results over heterogeneous areas using local simulations shows reliable precision of the spatialized model in the quantification of $L E, A_{C}$, albedo and FAPAR. These results demonstrate the importance of the scale change problem and open the way to larger applications.

Keywords: Remote Sensing, Heterogeneity, Latent Heat Flux, Photosynthesis, Albedo, fAPAR.

- F.A. Bouguerzaz and M. Raffy are with GRTS (Groupement de Recherche en Télédétection et Spatialisation) Parc d'Innovation, $5 \mathrm{Bd}$ S. Brant 67400 Strasbourg/Illkirch France

- A. Olioso is with INRA Bioclimatologie, Domaine Saint-Paul, F-84914 Avignon Cedex 9, France. E-mail: olioso@avignon.inra.fr Tel: 33-4-32 7224 06, Fax: 33-4-32 7223 62. Any correspondence should be addressed to Mr. Olioso.

(C) Canadian Journal of Remote Sensing/Journal canadien de télédétection 


\section{INTRODUCTION}

$\mathrm{R}$ emote sensing has the potential for providing synoptic surface information that is relevant to vegetation productivity and energy balance modelling. It is then necessary to use a physical model, simulating the energy and mass transfers between the soil, the vegetation and the atmosphere, which is able to assimilate data from remote sensing measurements (Delécolle et al., 1992, Olioso et al., 1999a). Soil-Vegetation-Atmosphere Transfer (SVAT) models have been implemented to relate remote sensing measurements (radiances) to the energy and water functioning of soil and vegetation canopies (Soer, 1980; Taconet et al., 1986; Hope et al., 1988; Van de Griend and Van Boxel, 1989; Lynn and Carlson, 1990; Olioso 1992). These models use simple, but realistic, descriptions of radiative, turbulent, and water transfers including the description of stomatal control of transpiration fluxes and, on some occasions, of photosynthetic fluxes. These models assume the knowledge of surface properties concerning vegetation and soil, such as canopy structure, albedo, absorption of radiation by the canopy, water status of the soil and the vegetation (stomatal conductance characteristics, capacity of water extraction by the roots, hydraulic characteristics of the soil, etc.). Various remote sensing data may be useful to drive SVAT models. Spectral reflectances in visible and near infrared may give information on the structure of vegetation canopies, as $\mathrm{LAI}$, albedo or the fraction of Absorbed Photosynthetically Active Radiation (fAPAR) (e.g., Jackson 1984, Asrar et al., 1984; Sellers 1985, Baret and Olioso 1989; Dugay and LeDrew 1992; Ottlé and Vidal-Madjar 1994; Sellers et al., 1996; Friedl 1996; Gillies et al., 1997). Thermal infrared is a privileged domain, since it is closely related to energy balance via surface temperature. It may give information on the soil or plant water status (e.g., Soer 1980; Camillo 1991; Kreis and Raffy 1993; Ottlé and Vidal-Madjar 1994; Olioso et al., 1996b; Friedl 1996; Gillies et al., 1997; Calvet et al., 1998).

SVAT models have usually been designed for homogeneous surfaces (they are generally based on "big-leaf" formulations, where landscapes are considered as having homogeneous surface characteristics). It is easy to identify the type of canopy and the relevant input parameters at the field level. At a larger scale, since SVAT models are non-linear, landscape heterogeneity can lead to substantial errors in the estimation of fluxes. This is what happens when employing remote sensing data (radiances) because of the low spatial resolution of many sensors that may be used for monitoring energy balance (e.g., thermal infrared from meteorological satellites such as NOAA or METEOSAT). However, only a few studies have analyzed the effect of spatially distributed surfaces and the potential errors caused by the estimation of fluxes from radiances over heterogeneous pixels: Sellers et al., (1992 and 1995) exploited the linearity between vegetation indices and some model parameters; Friedl (1996) also found a linear relationship between simulated fluxes and surface temperature; Moran et al., (1997) analyzed the scaling characteristics of fluxes in relation to remotely-sensed variables over heterogeneous landscape in semi-arid environment; Kreis and Raffy (1993) proposed to define effective media by inverting SVAT models against surface temperature measurements;
Raffy (1992 and 1994) defined 'spatialized' models and analyzed the errors due to scaling.

In this article, attention has been focused on the ability of the 'spatialized' model, as defined by Raffy (1992 and 1994), to reproduce the albedo $(\alpha), f A P A R$, the photosynthesis $\left(A_{c}\right)$, and the evapotranspiration $(L E)$ from reflectance and surface temperature measurements over heterogeneous areas. The ALiBi SVAT model (Olioso, 1992) has been used to compute $\alpha, f A P A R, A_{c}$ and $L E$, as well as spectral reflectances and surface temperature at the local scale for different surface conditions. The local data have been aggregated to a larger scale in order to simulate heterogeneous pixels. Then, we attempt to answer two questions:

1. Which models perform best to compute the four variables $\alpha, f A P A R, A_{c}$ and $L E$ from remotely-sensed radiances over a heterogeneous pixel ?

2. What are the biggest differences from real values of these variables?

\section{Description of the ALiBi Model (LOCAL SCALE)}

\section{1) Turbulent and Water Transfers, Photosynthesis}

The model used in this study has been described in detail by Olioso (1992 and 1996a; see also Bouguerzaz 1997). This model describes the soil (subscript $s$ ) and the vegetation (subscript $v$ ) energy balances. The energy balance for a vegetated surface (soil surface + vegetation canopy) is given by

$$
R_{n}=L E+H+G_{s} \quad\left(W m^{-2}\right)
$$

Soil surface and vegetation energy balances are also computed in order to take account of their different behaviours

$$
\begin{array}{lr}
R_{n v}=L E_{v}+H_{v} & \left(W m^{-2}\right) \\
R_{n s}=L E_{s}+H_{s}+G_{s} & \left(W m^{-2}\right)
\end{array}
$$

where $R_{n}=R_{n v}+R_{n s}\left(W \cdot m^{-2}\right)$ is the net radiation, $L E=L E_{v}+L E_{s}$ the latent heat flux (corresponding to evapotranspiration), $H=H_{v}+H_{s}$ the sensible heat flux and $G_{s}$ the ground heat flux. Each flux is computed following specific formulations considering meteorological boundary conditions at reference levels in the atmosphere and in the soil. As an illustration, the heat fluxes from the vegetation layer $\left(L E_{v}\right.$ and $\left.H_{v}\right)$ are expressed as

$$
\begin{aligned}
& L E_{v}=\frac{\rho c_{p}}{\gamma}\left(\frac{1}{g_{v}}+\frac{1}{h_{v}}\right)^{-1}\left(e_{v}^{*}\left(T_{v}\right)-e_{a c}\right) \\
& H_{v}=\rho c_{p} h_{v}\left(T_{v}-T_{a c}\right)
\end{aligned}
$$

with $\rho$ the air density, $c_{p}$ the air specific heat, $\gamma$ the psychometric constant, $h_{v}$ the turbulent transfer coefficient in leaf boundary 
layers, $g_{v}$ the vegetation surface conductance (which depends on leaf stomatal conductances), $e_{a c}$ and $T_{a c}$ the vapour pressure and the temperature of the air inside of the canopy, $e_{v}^{*}\left(T_{v}\right)$ the saturated vapour pressure at the vegetation surface temperature $T_{v}$. Stomatal conductances are computed as a function of incident $P A R$ at the leaf surface, leaf water potential, and vapour pressure deficit of the air at the leaf surface (as in Winkel and Rambal, 1990). The vegetation surface conductance is given by the sum of the leaf stomatal conductance over the whole canopy (see Olioso et al., 1996a). The heat fluxes from the soil $\left(L E_{s}\right.$ and $\left.H_{s}\right)$ are similarly described, but the soil surface conductance depends on the surface soil moisture. The various turbulent exchange coefficients involved in the calculations of heat fluxes (Figure 1) are related to canopy structure (height and LAI) and to the properties of the atmosphere (wind speed and stability).

The flux $L E_{v}$ is also expressed as a function of a hydraulic conductance $\left(G_{p}\right)$ and the difference of water potential between leaves $\left(\psi_{l}\right)$ and the soil in the root zone $\left(\psi_{s}\right)$ in order to describe the extraction of water by the roots:

$$
L E_{v}=G_{p}\left(\psi_{s}-\psi_{l}\right)
$$

The calculation of canopy photosynthesis $\left(A_{c}\right)$ follows a similar procedure as the calculation of surface vegetation conductance (Olioso et al., 1996a). It is obtained by the integration of the leaf photosynthesis over the whole canopy. The leaf photosynthesis is calculated as a function of incoming $P A R$ at leaf surface $\left(Q_{p}\right)$, leaf water potential $\left(\psi_{l}\right)$ and saturation deficit at leaf surface $\left(D_{0}^{\prime}\right)$ :

$$
A_{l}=A_{l \min }+\left(A_{l \max }-A_{l \min }\right) g_{a}\left(Q_{p}\right) g_{a}\left(\psi_{l}\right) g_{a}\left(D_{0}^{\prime}\right)
$$

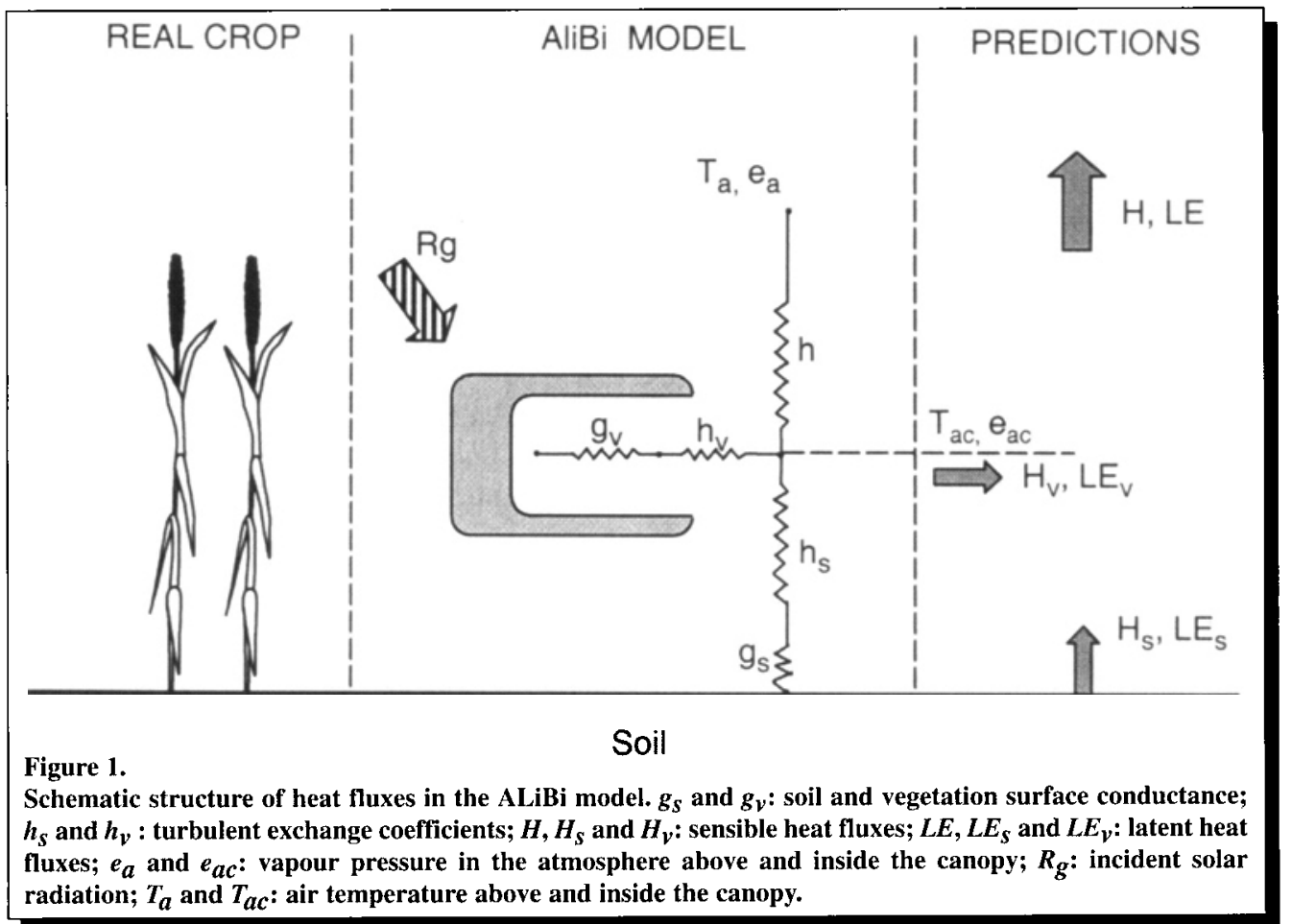

where $A_{l \text { min }}$ and $A_{l \text { max }}$ are the minimum and the maximum leaf photosynthesis, and each $g_{a}$ function varies between 0 and 1 . The integration from the leaf to the canopy uses radiative transfer to compute $g_{a}\left(Q_{p}\right)$ at the leaf surfaces and takes account of the hydraulic effects introduced by the term $g_{a}\left(\psi_{l}\right) g_{a}\left(D_{0}^{\prime}\right)$ which is calculated at the canopy scale:

$$
\begin{aligned}
A_{c}= & L A I c A_{l \min }+\left(A_{l \max }-A_{l \min }\right) g_{a}\left(\psi_{l}\right) g_{a}\left(D_{0}^{\prime}\right) \\
& \int_{0}^{L A I c} \int_{0}^{\pi / 2} \int_{0}^{2 \pi} g_{a}\left(Q_{p}\left(\varphi_{l}, \theta_{l}, L\right)\right) d \varphi_{f} d \theta_{f} d L
\end{aligned}
$$

where $\varphi_{l}$ and $\theta_{l}$ are the azimuth and zenith angles of leaves and $\mathrm{L}$ is the Leaf Area Index and LAIC its value for the whole canopy.

Resolution of energy balance (Equation 1) together with energy balance equations for the soil surface and the vegetation (Equations la and $1 \mathrm{~b}$ ) and the equation for water extraction (Equation 4) and turbulent fluxes (including Equation 2 and 3) makes it possible to compute the energy fluxes, the canopy photosynthesis and the soil and vegetation surface temperature $\left(T_{v}\right.$ and $T_{s}$ ). Main inputs are the meteorological forcing (air temperature and humidity, wind speed and incident radiations), parameters describing the canopy structure ( $L A I c$, height), the capacity of roots to extract water (represented by $G_{p}$ ), and the soil water status (surface soil moisture and root zone water potential).

\section{2) Radiative Transfers:}

The radiative transfers are described from the SAIL model, which was developed by Verhoef (1984 and 1985) to simulate directional spectral reflectance of vegetated surfaces. As part of the ALiBi model, the SAIL model is also used to simulate radiation absorption by the soil and the canopy (consequently the albedo), canopy emissivity and brightness temperature in the thermal infrared $\left(T_{b}\right)$, and $P A R$ distribution inside of the canopy (consequently $f A P A R$ ). For a single-layer uniform and homogeneous canopy, simulations depend upon the following parameters: biophysical parameters ( $L A I c$, Leaf inclination angle distribution); spectral parameters (leaf hemispherical reflectance and transmittance and soil hemispherical reflectance); illumination source parameters (solar zenith angle and fraction of incident diffused light) and view direction parameters (view zenith angle and relative azimuthal angle between the solar and view directions). In the solar domain, leaf optical properties are 
calculated using the PROSPECT model (Jacquemoud and Baret, 1990) as a function of only three parameters characterizing the leaf mesophyll structure $(\mathrm{N})$, the chlorophyll a $+\mathrm{b}$ concentration $\left(C_{a b}\right)$, and the water depth. The model used here takes into account the dry matter content introduced by Fourty and Baret (1996). In the thermal domain, specific optical properties are used: no leaf transmittance, low leaf and soil reflectances (0.04 and 0.05, respectively, corresponding to emissivity of 0.96 and 0.95 ).

The albedo $(\alpha)$ is computed by summing the canopy hemispherical reflectance over the whole solar spectrum:

$$
\alpha=\sum_{\lambda} \alpha_{\lambda} P_{\lambda}
$$

where $\lambda$ represents a spectral band, $\alpha_{\lambda}$ the hemispherical reflectance in this band, and $P_{\lambda}$ the proportion of solar energy in this band compared to the global radiation (actually, the calculation takes account of diffuse and direct radiations separately). Eleven bands, where the soil and the leaf optical properties were considered constant, were used over the whole solar spectrum.

The fraction of Absorbed Photosynthetically Active Radiation $(f A P A R)$ is calculated from the difference between the energy entering and leaving the canopy:

$$
f A P A R=\frac{A P A R}{P^{\prime} R_{0}}
$$

with

$$
A P A R=P A R_{0}+P A R_{r s}-\left(P A R_{r}+P A R_{t}\right)
$$

where $P A R_{0}$ is the incident radiation at the top of the canopy, $P A R_{t}$ the radiation transmitted by the canopy to the soil, $P A R_{r s}$ the radiation reflected at the soil surface and $P A R_{r}$ the upward radiation reflected by the vegetated surface.

The infrared brightness temperature $\left(T_{b}\right)$ is computed from the vegetation $\left(T_{\nu}\right)$ and the soil $\left(T_{s}\right)$ surface temperatures (which are solutions of energy balance equations), through a radiative transfer description including the effect of incident atmospheric radiation in the measurement waveband $\left(R_{g \lambda \downarrow, \lambda}\right)$ :

$$
\begin{aligned}
f_{\lambda}\left(T_{b}\right) & =\epsilon_{v, d, \lambda} f_{\lambda}\left(T_{v}\right)+\tau_{t, d, \lambda} \epsilon_{s, d, \lambda} f_{\lambda}\left(T_{g}\right) \\
& +\rho_{t, d, \lambda} R_{g \lambda \downarrow, \lambda}
\end{aligned}
$$

where $\epsilon_{v, d, \lambda}$ and $\epsilon_{s, d, \lambda}$ are the vegetation and soil emissivity in the direction of observation (the subscript $d$ refers to the directionality of the viewing), $\tau_{t, d, \lambda}$ the vegetation transmission coefficient for thermal radiation, $\rho_{t, d, \lambda}$ the canopy reflection coefficient, $f_{\lambda}\left(T_{b}\right)$ a function of the temperature to calculate the thermal emission in the measurement waveband (Olioso, 1995).

\section{Description of THE SPATIALized MODEL}

In the following, we consider one soil-pixel $\Omega$ (i.e., the IFOV, the Instantaneous Field Of View) of an area $|\Omega|$ and $\omega \epsilon \Omega$ a current point of the surface. The point $\omega$ can be considered as a microscopic pixel with local multi-spectral radiances:

$$
\vec{\ell}(\omega)=\left(\ell_{1}(\omega), \ell_{2}(\omega), \ldots \ldots \ell_{n}(\omega)\right)
$$

These radiances are naturally bounded for $\omega \epsilon \Omega$. Then, we consider a bounded domain $D \epsilon I R^{n}$, which satisfies the condition:

$\vec{\ell}(\omega) \epsilon D$ for $\omega \epsilon \Omega$

In the natural environment observed by radiometry, the media $k$ called "homogeneous" corresponds, generally, to a convex zone $\mathrm{D}_{\mathrm{k}}$ of little extent in the spectral domain which satisfies the condition $\mathrm{D}_{\mathrm{k}} \subset \mathrm{D} ;(\forall \mathrm{k}=1$ to $\mathrm{K})$.

At the global scale, the ' $n$ ' measurable radiances on $\Omega$ are:

$$
\overrightarrow{\mathrm{L}}(\Omega)=\left(\mathrm{L}_{1}(\Omega), \mathrm{L}_{2}(\Omega), \ldots \ldots \mathrm{L}_{n}(\Omega)\right)
$$

If we assume that all the atmospheric corrections are done and a perfect sensor, the radiances measured by the sensor in the $\mathrm{i}^{\text {th }}$ channel is:

$$
L_{i}(\Omega)=\frac{1}{|\Omega|} \int_{\Omega} \ell_{i}(\omega) d \omega
$$

Physical models used in remote sensing describe the dependence of a physical parameter $\varphi$ to the measured radiance $\vec{\ell}(\omega)$ at every point $\omega$ of the area. Then for each $\omega$ this parameter is expressed by a relation to $\vec{\ell}(\omega)$ of the form:

$$
\varphi=\mathrm{R}(\vec{\ell}(\omega)), \quad \forall \omega \epsilon \Omega
$$

In the most general case, the actual value we aim to reach is

$$
r_{\vec{\ell}}(\vec{L})=\frac{1}{|\Omega|} \int_{\Omega} \mathrm{R}(\vec{\ell}(\omega)) d \omega
$$

For the instrument that observes $\Omega$, all the distributions $\vec{\ell}$ defined on $\Omega$ and satisfying Equations 11 and 13 constitute a class of indistinguishable signals (Figure 2). Let us note this class $\mathfrak{I}_{\overrightarrow{\mathrm{L}}}$. Raffy (1994) shows that the set of all the possible in situ values of $\mathrm{r}_{\vec{\ell}}(\overrightarrow{\mathrm{L}})$ defined by Equation 15 when $\vec{\ell}(\omega) \boldsymbol{\epsilon}_{\overrightarrow{\mathrm{L}}}$ constitute exactly an interval:

$$
\mathrm{r}_{\ell}(\overrightarrow{\mathrm{L}}) \epsilon\left[\mathrm{R} \vee(\overrightarrow{\mathrm{L}}), \mathrm{R}^{\wedge}(\overrightarrow{\mathrm{L}})\right]
$$




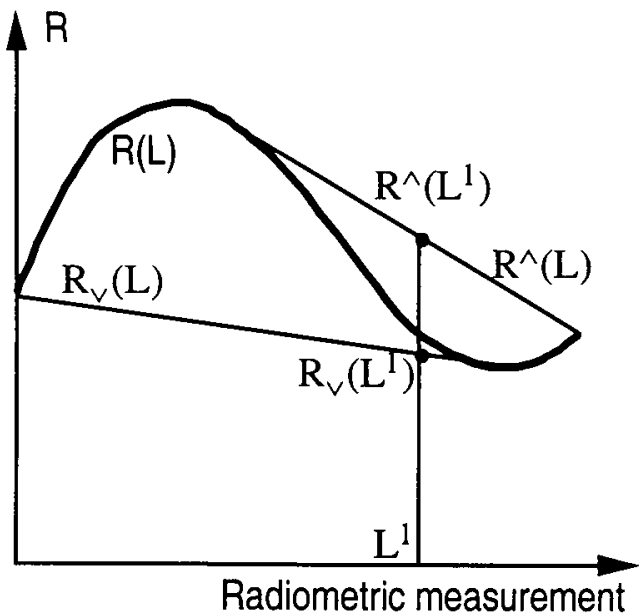

Figure 2.

Representation of a model $R$ (thick line) in the case of one radiometric dimension. $R_{\text {and }} R^{\wedge}$ (thin lines) are the bounds of the convex hull defined by the graph of $R$. For a given radiance $L^{1}$ the spatialized method gives $\mathrm{R}\left(L^{1}\right)$ and $\mathrm{R}^{\wedge}\left(L^{1}\right)$.

where $R_{\vee}$ and $R^{\wedge}$ are the bounds of the convex hull defined by the graph of $R$. This interval defines the maximum gap that might occur between $r_{\vec{t}}(\vec{L})$ and the computed value $\mathrm{R}(\overrightarrow{\mathrm{L}})$ obtained with the model $\mathrm{R}$ applied at the heterogeneous pixel scale with the radiance data $\overrightarrow{\mathrm{L}}$ :

$$
\epsilon_{\mathrm{R}}(\overrightarrow{\mathrm{L}})=\mathrm{R}^{\wedge}(\vec{L})-R_{\vee}(\overrightarrow{\mathrm{L}})
$$

This gap depends on the non-linearity of $\mathrm{R}$ and the heterogeneity of the pixel $\Omega$. Without any information on the distribution $\vec{\ell}$, we consider that $r_{\ell}(\vec{L})$ is uniformly distributed within $\left[\mathbf{R}_{\vee}(\vec{L}), \mathrm{R}^{\wedge}(\vec{L})\right]$ when $\vec{\ell} \epsilon D$. In this situation, the model which minimizes, in the mean, the error due to the change of scale in the heterogeneous pixel $\Omega$ is:

$$
\mathfrak{H}(\overrightarrow{\mathrm{L}})=\frac{1}{2}\left[\mathrm{R}(\overrightarrow{\mathrm{L}})+\mathrm{R}^{\wedge}(\overrightarrow{\mathrm{L}})\right] ; \quad \overrightarrow{\mathrm{L}} \in \mathrm{D}
$$

Following Raffy (1992, 1994), this model is called the spatialized model.

Let us apply the spatialized model to the variables computed by the ALiBi model at the local scale. Despite the complexity of the terms intervening in the ALiBi model, the latter can take the general form $R(\vec{\ell}(\omega), \vec{p}(\omega))$ where $\vec{\ell}(\omega)=\left(\ell_{R}(\omega), \ell_{N / R}(\omega)\right.$, $\ell_{T I R}(\omega)$ ) is the reflectance in red (R) and near-infrared (NIR) bands and the thermal radiometry (TIR) and $\vec{p}(\omega)$ is a vector containing characteristic parameters of each homogeneous medium (vegetation structure, physiological characteristics of plants, soil and plant water status). The variables to spatialize can be classified in two categories:

a) the variables computed by taking into account radiative processes only: $\alpha$ and $f A P A R$. They are related to the canopy behaviour in the visible and near-infrared domains. In this case we consider only the reflectances $\left(\ell_{R}(\omega), \ell_{N I R}(\omega)\right)$, and the model value $R(\vec{\ell}(\omega), \vec{p}(\omega))$ to spatialize the variables: $\alpha(\vec{\ell}(\omega), \vec{p}(\omega))$, and $\operatorname{fAPAR}(\vec{\ell}(\omega), \vec{p}(\omega))$. b) the evapotranspiration $(L E)$ and the photosynthesis $\left(A_{C}\right)$ : in addition to the reflectances, we introduced the thermal infrared radiance $\ell_{T I R}(\omega)$ to spatialize $L E(\vec{\ell}(\omega), \vec{p}(\omega))$ and $A_{c}(\vec{\ell}(\omega), \vec{p}(\omega))$.

\section{EXPERIMENTAL MEASUREMENTS AND Construction of Heterogeneous LANDSCAPES (Global SCALE)}

To simulate an agricultural type landscape, we consider three canopy covers, wheat, maize and soybean, and bare soils. Each type of cover is simulated in different physiological and phenological states. In the present case, the physiology and the phenology of a canopy cover are characterized by a set of input parameters of the model $\vec{p}(\omega)$. To simulate realistic landscapes we make a selection from among a variety of parameters whose variation limits are related to the type of cover. This set of parameters allows us to simulate the three covers in several possible states (state of growth, water status of soil and plants) while remaining within the limits of reality. For all these covers, physiological, biological and soil parameters are involved: leaf area index $(L A I c)$, vegetation height $(h)$, soil moisture (in the surface layer and in the root zone), leaf angle distribution (the Beta distribution described by Goel and Thomson (1984) is used), leaf optical properties, hydraulic conductance $\left(G_{p}\right)$ and parameters for the response functions of stomatal conductance and leaf photosynthesis (involved in functions $g_{a}$ ). Air temperature $\left(T_{a}\right)$, air vapour pressure $\left(e_{a}\right)$, wind speed $\left(u_{a}\right)$, all at a reference height above the canopy, and incident global radiation constitute the meteorological forcing at each time step of the model (every 15 minutes). We have also simulated, through the variation of the soil hemispherical reflectance, the spectral reflectance of bare soil of different types varying by its brightness from a dark soil to a bright soil.

Changing the input parameters, we can simulate each cover on two different dates: one in June and the other in September. In June, the media composing the covers are at a different state of growth from media to media, e.g., the wheat is more developed than the maize or soybean, considering its high LAI. On another hand we can also change the cover and the soil moisture state by considering several values of the surface soil moisture $\theta_{[0-5]}$ and the hydraulic conductance $G_{p}$. Those two parameters have a great influence on the estimation of some of the variables, particularly those variables which depend on hydraulic effects. We should also bear in mind that the aerodynamic and meteorological conditions change between the two dates because June is generally a drier month than September. Those conditions are described by the meteorological variables, aerodynamic parameters and incident radiations. Table 1 gives the limits of variation of the parameters selected to simulate the three covers in June and September. The parameters concerning the soybean and wheat canopies are obtained from field experiments conducted at INRA Research Center near Avignon (France, 43⒌ $4^{\prime}$ N, 448' E) (Olioso, 1992; Gonzalez-Dunia, 1995, Olioso et al., 1999b). Another set of parameters is obtained 
Table 1.

Variation limits of input parameters for the simulations of the three covers: wheat, maize and soybean. $A_{f \min }=-1.0\left(\mu\right.$ mole $\left.\mathrm{m}^{-2} \mathrm{~s}^{-1}\right)$ and $\mathrm{g}_{f \min }=\left(0.0001 \mathrm{~ms}^{-1}\right)$

\begin{tabular}{|c|c|c|c|}
\hline Parameters $\vec{p}$ & Wheat & Maize & Soybean \\
\hline $\begin{array}{l}\text { LAIc (Canopy Leaf } \\
\text { Area Index) }\end{array}$ & $\begin{array}{l}\text { June: } 4 \text { - } 8 \\
\text { September: } 0.0\end{array}$ & $\begin{array}{l}\text { June: } 0.95-4 \\
\text { September: } 3-8\end{array}$ & $\begin{array}{l}\text { June: } 0.5-4.5 \\
\text { September: } 3-7\end{array}$ \\
\hline $\mathrm{h}$ (canopy height in $m$ ) & $\begin{array}{l}\text { June: } 0.7-0.0 \\
\text { September: } 0.0\end{array}$ & $\begin{array}{l}\text { June: } 0.45-1.0 \\
\text { September: } 1.4-2.5\end{array}$ & $\begin{array}{l}\text { June: } 0.1-0.9 \\
\text { September: } 0.4-1.0\end{array}$ \\
\hline $\begin{array}{l}\mathrm{N} \text { (leaf structure } \\
\text { parameter) }\end{array}$ & $1.3-1.5$ & $1.0-1.45$ & $1.3-1.86$ \\
\hline$C_{a b}\left(\mu_{\mathrm{gcm}^{-2}}\right)$ & $30.0-55.0$ & $25.0-40.0$ & $35.0-50.0$ \\
\hline$A_{f \max }\left(\mu_{\text {mole }} \mathrm{m}^{-2} \mathrm{~s}^{-1}\right)$ & $25.0-35.0$ & $45.0-55.0$ & $25.0-35.0$ \\
\hline$g f \max \left(m s^{-1}\right)$ & $0.0123-0.0166$ & $0.0142-0.0171$ & $0.0123=0.0166$ \\
\hline$G_{p}\left(W m^{-2} / M P a\right)$ & $\begin{array}{l}\text { moist: } 350-550 \\
\text { dry: } 150-300\end{array}$ & $\begin{array}{l}\text { moist: } 350-550 \\
\text { dry: } 150-300\end{array}$ & $\begin{array}{l}\text { moist: } 350-550 \\
\text { dry: } 150-300\end{array}$ \\
\hline$\theta_{[0-5]}\left(\mathrm{m}^{3} / \mathrm{m}^{3}\right)$ & $\begin{array}{l}\text { moist: } 0.15-0.30 \\
\text { dry: } 0.05-0.10\end{array}$ & $\begin{array}{l}\text { moist: } 0.15-0.30 \\
\text { dry: } 0.05-0.10\end{array}$ & $\begin{array}{l}\text { moist: } 0.15-0.30 \\
\text { dry: } 0.05-0.10\end{array}$ \\
\hline
\end{tabular}

from an experiment on Maize (in Grignon near Paris, in 1994: unpublished data).

The variability in the parameters make it possible to generate a variability in canopy spectral reflectances, thermal infrared radiance, and fluxes. The difference between the simulations of diurnal evolution of albedo and $f A P A R$ in the case of young and developed media is shown in Figure 3 for June. For the same media, the input parameters differ between its early growth ( $L A I C=0.95$ for maize and 0.5 for soybean) and developed state $(L A I C=3.5$ for maize and 4.25 for soybean). More precisely, the LAI is higher for the developed media. We remark on this figure that for the same type of media, the albedo and $F P A P A R$ increase with increasing LAI.

Figures $\mathbf{4 a}$ and $\mathbf{4 b}$ illustrate the repartition of red and near-infrared reflectances $\left(\ell_{R}(\omega), \ell_{N I R}(\omega)\right)$ in the radiometric domain and the diurnal evolution of brightness temperature simulations, respectively. We can see that the higher the moisture the lower the temperature. This temperature is transformed into a radiometric measure $\ell_{T I R}(\omega)$ from relation (Equation 10). Increases in red and NIR reflectances mainly result from an increase in LAI. For the same vegetation type, the more developed covers (high LAI and $C_{a b}$ ) have a higher chlorophyllian activity (lower red reflectance) and a higher internal diffusion of the infrared radiation (yielding a higher NIR reflectance). An important point deserves some clarification. In the (red, NIR) domain when maize and soybean are in the same growth state, the convex envelopes characterized by the $D_{k}$ domains almost overlap in $I R^{2}$. On the other hand if we add the thermal channel, the convex domains $D_{k}$ characterizing the covers in $I R^{3}$ are more separated (but still overlapping).
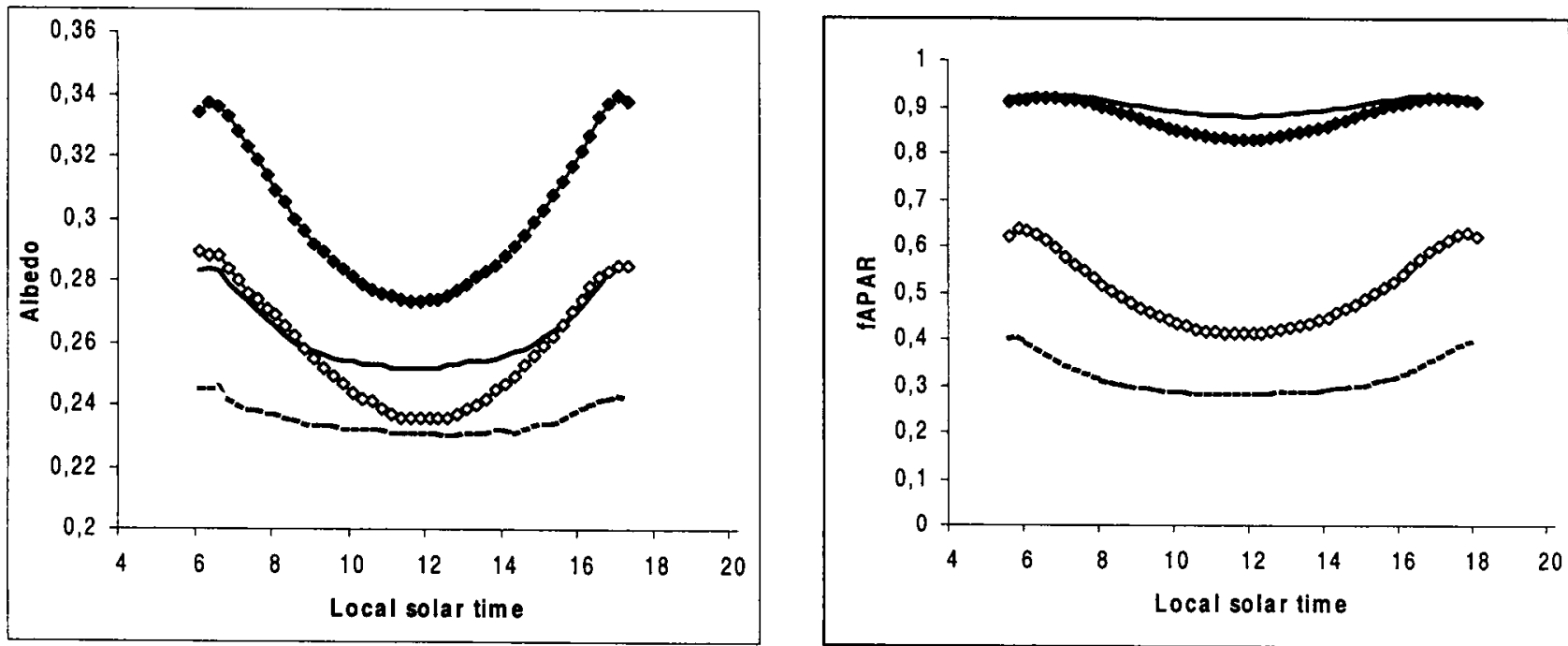

Figure 3.

Diurnal evolution of albedo and fraction of absorbed photosynthetically active radiation $($ APAR) simulations on selected input parameters. $\longrightarrow-$ early growth maize $(L A I C=0.95) ;-\bullet-$ developed maize $(L A I C=3.5) ;----$ early growth soybean $(L A I c=0.5) ;-$ developed soybean $(L A I c=4.25)$. 

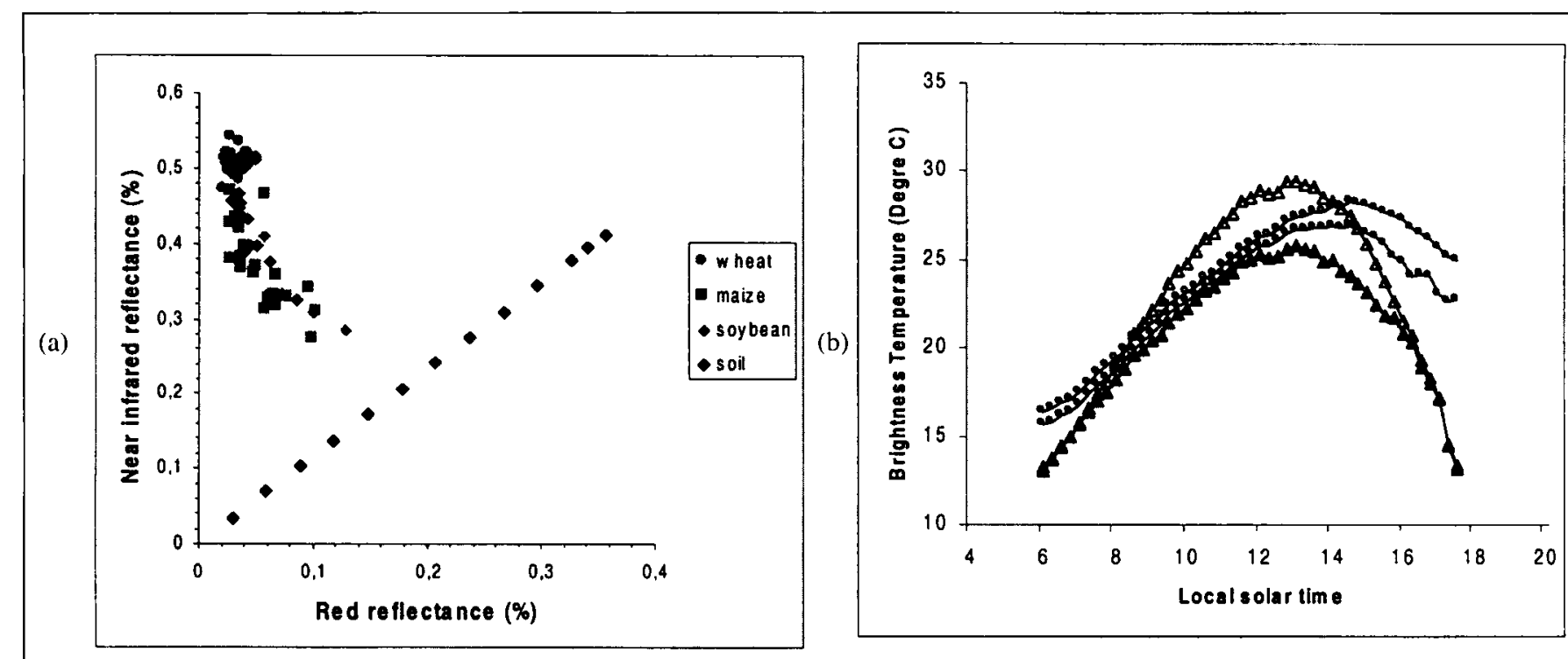

Figure 4.

Radiometric data simulated to construct the domain D. (a) Red and near-infrared reflectances of the media used to simulate a landscape in June. (b) Diurnal evolution of brightness temperature simulations in degree Celsius on selected input parameters. - $-\mathrm{dry}$ maize $\left(G_{p}=277^{-2} \mathrm{Wm}^{-2} / \mathrm{MPa}\right.$; $\left.\theta_{[0-5]}=0.109 \mathrm{~m}^{3} / \mathrm{m}^{3}\right) ; \longrightarrow$ moist maize $\left(G_{p}=463 \mathrm{Wm}^{-2} / \mathrm{MPa} ; \theta_{[0-5]}=0.185 \mathrm{~m}^{3} / \mathrm{m}^{3}\right) ; \triangle \triangle$ dry soybean $\left(G_{p}=285 \mathrm{Wm}^{-2} / \mathrm{MPa}^{2} \theta_{[0-5]}=0.089 \mathrm{~m}^{3} / \mathrm{m}^{3}\right) ;$ -A-moist soybean $\left.\left(G_{p}=530 \mathrm{Wm}^{-2} / \mathrm{MPa}\right) ; \theta_{[0-5]}=0.185 \mathrm{~m}^{3} / \mathrm{m}^{3}\right)$.

Examples of diurnal simulation of $A_{c}$ and $L E$ in September are illustrated on Figure 5. They show the influence of moisture on these variables. Input characteristics parameters $\vec{p}_{m}\left(\omega_{j}\right)$ for maize and $\vec{p}_{s}\left(\omega_{j}\right)$ for soybean are taken. The difference in moisture state is expressed by the hydraulic conductance $G_{p}$ and the surface soil moisture $\theta_{[0-5]}$. Those figures show characteristic shapes for the diurnal courses of photosynthesis and latent heat flux. We can see first a dissymmetric behaviour for photosynthesis with a depletion in the afternoon, which depends on the water stress. Latent heat fluxes exhibit more symmetric curve. The apparition of a 'plateau', which increases with water stress, may be noticed (see Olioso et al., 1996a). We can see that both photosynthesis and latent heat flux are very sensitive to the moisture state of the media.

The simulation of this variability is necessary to create different degrees of spatial heterogeneity. Indeed, one can simulate a heterogeneous scene made of different quasi-homogeneous media. Quasi-homogeneity here refers to the fact that the same type of canopy cover may be in different physiological, biophysical and water status. Spatial heterogeneity is increased
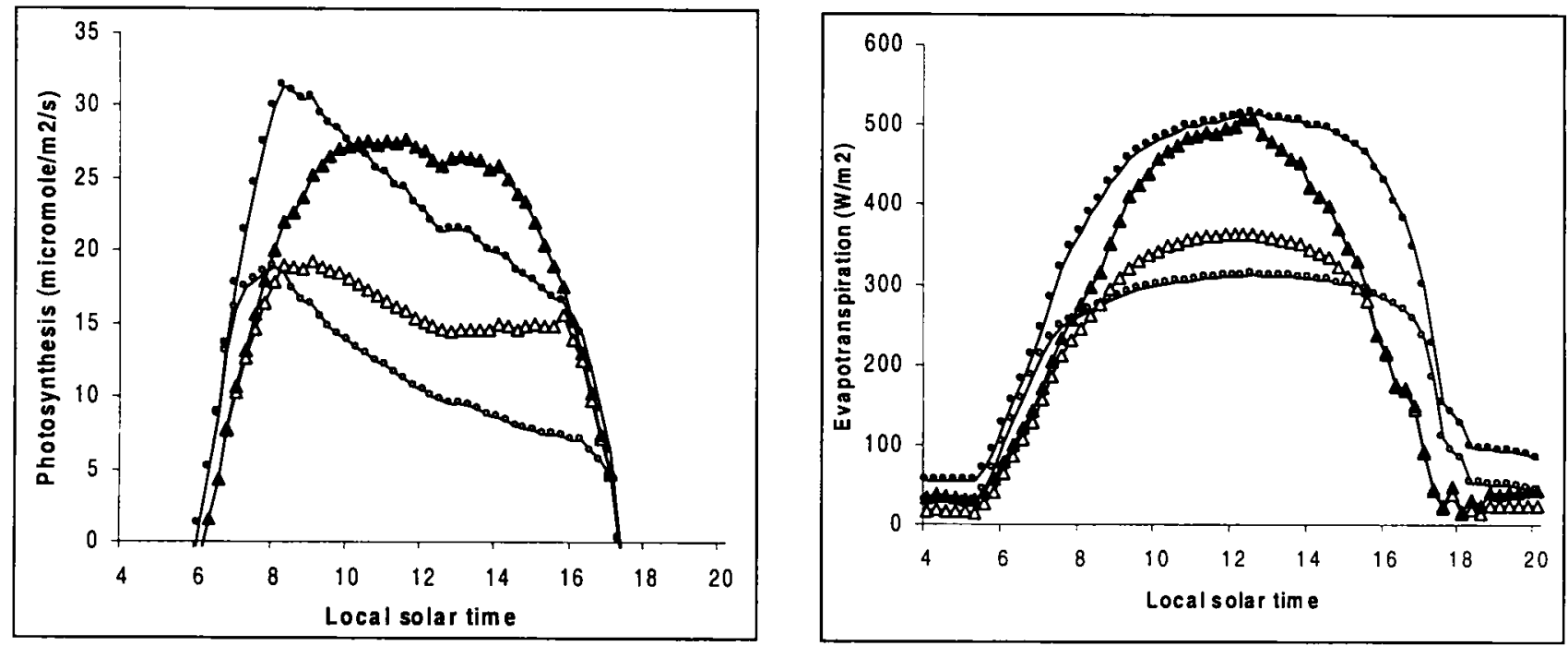

Figure 5.

Diurnal evolution of photosynthesis and evapotranspiration simulations on selected input parameters. $-0-\mathrm{dry}$ maize $\left(G_{p}=277 \mathrm{WIn} / \mathrm{MPa}\right.$; $\left.\theta_{[0-5]}=0.109 \mathrm{~m}^{3} / \mathrm{m}^{3}\right) ; \longrightarrow$ moist maize $\left(G_{p}=463 \mathrm{Wm}^{-2} / \mathrm{MPa} ; \theta_{[0-5]}=0.185 \mathrm{~m}^{3} / \mathrm{m}^{3}\right) ;-\triangle$ dry soybean $\left(G_{p}=285 \mathrm{Wm}^{-2} / \mathrm{MPa}^{2} ; \theta_{[0-5]}=0.089 \mathrm{~m}^{3} / \mathrm{m}^{3}\right)$; -A- moist soybean $\left.\left(G_{p}=530 \mathrm{Wm}^{-2} / \mathrm{MPa}\right) ; \theta_{\{0-5\}}=0.185 \mathrm{~m}^{3} / \mathrm{m}^{3}\right)$. 
when one considers the three types of cover and bare soil. The values of reflectances, radiances and variables simulated at 14:00 local solar time are considered in the following of this study. The main reason lies in the fact that this corresponds to the time of NOAA-AVHRR overpasses.

An agricultural scene is simulated at the local scale to represent a natural heterogeneous landscape. It represents a reference scene constituting a spatial grid of $100 \times 100$ local pixels $\omega_{j}\left(j=1\right.$ to $\left.100^{2}\right)$. Each pixel $\omega_{\mathrm{j}}$ is considered as homogeneous in the sense that only one medium covers it. Then each pixel $\omega_{j}$ is characterized by a vector $\left(\vec{\ell}\left(\omega_{j}\right), R_{k}\left(\vec{\ell}\left(\omega_{j}\right), \vec{p}_{k}\left(\omega_{j}\right)\right)\right.$ and linked to the type and state of the medium " $k$ " that covers it ( $k=1$ to 4 ). This same scene is simulated at the global scale by incorporating the local pixels $\omega_{j}$ within blocks of $10 \times 10$ pixels. Then we obtain 100 new heterogeneous pixels $\Omega$. So pixels $\Omega$ at a global scale constitute a mixture of wheat, maize, soybean and bare soil. For each pixel $\Omega$, reflectances and thermal radiances $\left(L_{R}(\Omega), L_{N I R}(\Omega), L_{T I R}(\Omega)\right.$ are obtained by averaging the data $\left(\ell_{R}(\omega), \ell_{N I R}(\omega), \ell_{T I R}(\omega)\right)$ of local pixels according to Equation 13. In the same way, $\Omega$ is calculated with the actual values $\mathrm{r}_{\vec{\ell}}(\overrightarrow{\mathrm{L}})$ of the variables $\alpha, f A P A R, A_{c}$ and $L E$ as defined by Equation 15.

In order to analyze the error of spatialization as a function of the type of mixture and the degree of heterogeneity, we simulate four scenes representing different heterogeneous types of landscapes in June and four in September: the composition of the scenes is given in Table 2. These scene compositions correspond to the case of the albedo and $f A P A R$ spatialization with the data simulated in June. For photosynthesis and evapotranspiration, we use the data collected in September to simulate reflectances, brightness temperature and variables. The wheat being sown in September, we consider the same composition of the scenes by replacing the proportion of wheat by maize and soybean. Then, for $A_{c}$ and $L E$, which depend on hydraulic effects conversely to $F A P A R$, we study the effect of the media moisture state on the error of spatialization. The difference in moisture state is expressed by the hydraulic conductance $G_{p}$ and the soil moisture $\theta_{[0-5]}$. Four states of moisture are considered in the four precedent scenes: they are given in Table 2 .

\section{RESULTS AND DisCUSSION}

For each pixel $\Omega$, where the measured radiance is $\overrightarrow{\mathrm{L}}(\Omega)$, the maximum deviation between the actual in situ value of the variable given by Equation 15 and the global computable value $\mathrm{R}(\overrightarrow{\mathrm{L}}(\Omega))$ is given by $\mathrm{R}^{\wedge}(\overrightarrow{\mathrm{L}}(\Omega))-\mathrm{R}_{\vee}(\overrightarrow{\mathrm{L}}(\Omega))$ (Raffy, 1992,1994). Then,

$$
\mathrm{E} 1=\frac{1}{\mathrm{~N}} \sum_{\mathrm{i}=1}^{\mathrm{N}}\left(\mathrm{R}^{\wedge}\left(\overrightarrow{\mathrm{L}}\left(\Omega_{\mathrm{i}}\right)\right)-\mathrm{R}^{\vee}\left(\overrightarrow{\mathrm{L}}\left(\Omega_{\mathrm{i}}\right)\right)\right)
$$

expresses the average possible deviations for $\mathrm{N}$ pixels (here, $\mathrm{N}=100$ ).
The relative mean deviation is:

$$
\mathrm{E} 2=\frac{1}{\mathrm{~N}} \sum_{\mathrm{i}=1}^{\mathrm{N}} \frac{\left(\mathrm { R } ^ { \wedge } \left(\overrightarrow{\mathrm{L}}\left(\Omega_{\mathrm{i}}\right)-\mathrm{R}^{\vee}\left(\overrightarrow{\mathrm{L}}\left(\Omega_{\mathrm{i}}\right)\right)\right.\right.}{\mathrm{r}_{\vec{\ell}}\left(\overrightarrow{\mathrm{L}}\left(\Omega_{\mathrm{i}}\right)\right)}
$$

and the relative error, E3, when we apply the spatialized model:

$$
\mathrm{E} 3=\frac{1}{\mathrm{~N}} \sum_{\mathrm{i}=1}^{\mathrm{N}}\left(\frac{\left|\mathrm{r}_{\vec{\ell}}\left(\overrightarrow{\mathrm{L}}\left(\Omega_{\mathrm{i}}\right)\right)-\Re\left(\overrightarrow{\mathrm{L}}\left(\Omega_{\mathrm{i}}\right)\right)\right|}{\mathrm{r}_{\vec{\ell}}\left(\overrightarrow{\mathrm{L}}\left(\Omega_{\mathrm{i}}\right)\right)}\right)
$$

\section{SPATIALIZATION OF $\alpha, f A P A R, A_{C}$}

\section{AND $L E$ :}

The graphs of the mean values of the variables and errors E1 over the scenes, as a function of scene heterogeneity and moisture states are presented in Figure 6 for $\alpha, f A P A R, A_{C}$ and $L E$. The mean value represents the average of the variable over the entire scene. We can see that the mean values of the variables vary in agreement with the scene composition. Most of the variables have their lowest value in the Scene No.1 since it is composed of a high percentage of bare soil, which has no PAR absorption or photosynthesis. This is not always the case for $L E$, depending on the moisture state of the scene, since wet bare soil may have a large evaporation. Highest values usually occur in the Scene No.4 which is composed of a large proportion of vegetation. We can also see that $A_{c}$ and $L E$ are higher for a moist cover than for a dry cover: state No.4 has the highest $A_{c}$ and $L E$ values for all the scenes, because all its media are in a moist state; conversely, state No.1, in which all media are dry has the lowest values.

\section{Table 2.}

Composition of the four scenes both in June and in September (mean proportions $\left|\Omega_{k}\right|$ of each media in the different pixels $(\Omega)$ for each scene), and of the four moisture states.

\begin{tabular}{|l|l|c|c|c|c|}
\hline \hline & & Maize & Wheat & Soybean & Bare Soil \\
\hline Scene 1 & June & $41 \%$ & - & - & $59 \%$ \\
& September & $41 \%$ & - & - & $59 \%$ \\
\hline Scene 2 & June & $10 \%$ & $37 \%$ & $10 \%$ & $43 \%$ \\
& September & $28.5 \%$ & - & $28.5 \%$ & $43 \%$ \\
\hline Scene 3 & June & $31.5 \%$ & $10 \%$ & $15 \%$ & $43.5 \%$ \\
& September & $36.5 \%$ & - & $20 \%$ & $43.5 \%$ \\
\hline Scene 4 & June & $35 \%$ & $35 \%$ & $24 \%$ & $6 \%$ \\
& September & $52.5 \%$ & - & $41.5 \%$ & $6 \%$ \\
\hline Moisture State 1 & September & dry & - & dry & dry \\
Moisture State 2 & September & dry & - & moist & dry \\
Moisture State 3 & September & moist & - & dry & dry \\
Moisture State 4 & September & moist & - & moist & moist \\
& & \multicolumn{2}{|c|}{} & & \\
\hline
\end{tabular}



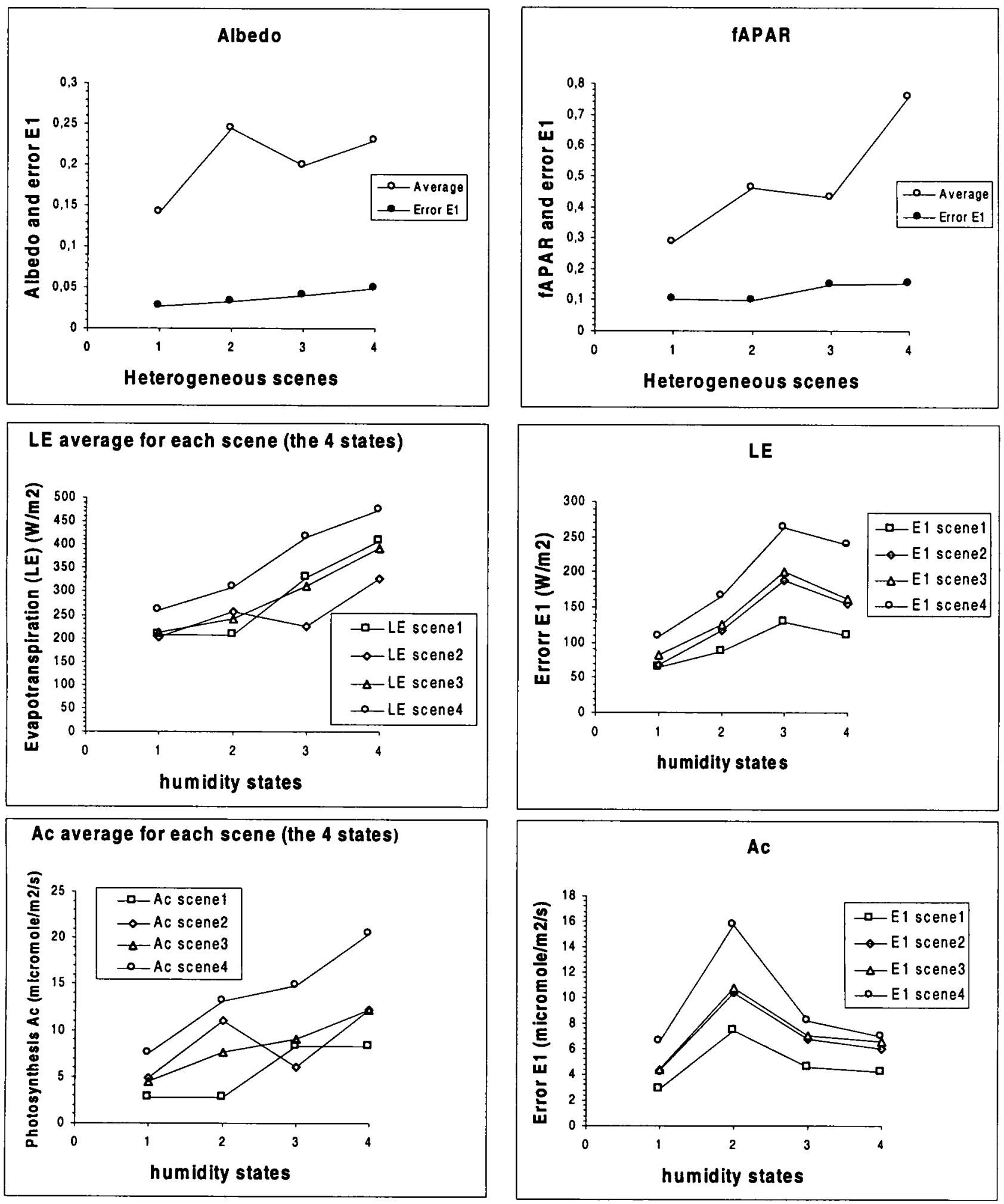

Figure 6 .

Average, over the scene, of variable to spatialize and the maximum gap (E1) due to the heterogeneity as function of the scene and the humidity state. 
We observe, for all the variables, that the maximum error due to the heterogeneity (El which represents the mean of the range of each variable for given values of the radiances) increases with the scene number. This is consistent with the scene heterogeneity, which is also increasing. We notice that the errors $\mathrm{El}$ are low for albedo and $f A P A R$, while large values occur for $A_{c}$ and $L E$. For these two last variables, the error E1 is often just lower than the actual value of the variable and sometimes even greater. Indeed, the error E1 reaches about 15 micromole $/ \mathrm{m} 2 / \mathrm{s}$ for an $A_{c}$ mean value of $13 \mathrm{micromole} / \mathrm{m} 2 / \mathrm{s}$ in Scene No.4, state No.2. For $A_{c}$, the moisture state No.2 is the one that gives the greatest error $E 1$ for each scene; for $L E$ it is the moisture state No.3 that gives the greatest error.

Figure 7 presents the relative errors due to the heterogeneity (E2) and the relative spatialized errors (E3 obtained when using the spatialized model) for all the variables as a function of the scene number and moisture states. Error E2 is around 15-20\% for $\alpha$ and 20-35\% for fAPAR. For those variables, error E3 is less than $5 \%$. The error E2 is greater for $L E$ (between 30 and $80 \%$ ) and even more for $A_{c}$ (between $30 \%$ and $150 \%$ ). As for $\mathrm{E} 1$, the higher values of E2 are in moisture state No. 2 for $A_{c}$ and in moisture state No. 3 for $L E$. In the case of $L E$, and for each scene, we can see that the relative error E2 is lower when all the media are in the same moisture state (state No.1, all are dry, and No.4, all are wet). This is different for $A_{c}$, the lowest errors occurred only for state No. 4 . Considering the scene number, the highest errors usually occurred for Scene 4 and 1 in the case of $L E$ and 3 and 1 in the case of $A_{C}$. Errors E3 are always smaller than E2. They are lower than $25 \%$ for $L E$ (below $10 \%$ except for Scene 2) and lower than $60 \%$ for $A_{c}$ (below $30 \%$ except for Scene 1). As for E2, the lower errors E3 usually occurred in moisture states No.1 and 4 for $L E$ and moisture state No. 4 for $A_{c}$. The largest errors E3 usually occurred for Scene 2 in the case of $L E$, and for Scene 1 in the case of $A_{c}$.

The small errors (E1, E2 and E3) obtained for albedo and fAPAR show that the estimation of these variables from reflectance measurements in the red and the near-infrared is quite insensitive to the heterogeneity of the observed scene. Actually, this means that models relating reflectances to albedo and $f A P A R$ are almost linear. Indeed, in many studies, the albedo was computed from a weighted average of reflectance in several spectral bands (Jackson 1984, Wydick et al., 1987, Toll 1989, Wang and LeDrew 1989, Duguay and LeDrew 1992). Estimations were usually based on more than 2 spectral bands, in contrast to the present study, to account for spectral reflectance variations in the visible and for reflectances in the middle infrared. However, two spectral bands, one in the visible and one in the near-infrared, may be enough: most of the incident solar energy is present in these two domains and variations in spectral reflectances (due to change in surface state) in these two domains are actually rather spectrally homogeneous. fAPAR presents larger errors than albedo, but these errors are still low. Many studies have also found quasi-linear relationships between $f A P A R$ and vegetation indices (Asrar et al., 1984, Sellers 1985, Baret and Olioso 1989).
The large errors E1 and E2 obtained for $L E$ and $A_{c}$ show that the estimation of these variables from reflectances and thermal measurements is sensitive to the heterogeneity of the observed scene. The analysis of these errors is a difficult task. Different sources of heterogeneity affect the calculation of the convex hull which defines $R_{\vee}$ and $R^{\wedge}$ : the number of different types of surfaces; the type and phenological stage of plants constituting the surfaces; and the water status of the surfaces. These factors affect the variability of the investigated variables, $L E$ and $A_{c}$, as well as the variability of the radiances. "Measured" values of radiances also depend on the proportion of the different surfaces constituting the scene; these "measured" values determined the domain inside of the convex hull, which is taken into account in error calculations. The intervals between $R_{\vee}$ and $R^{\wedge}$, and then errors $\mathrm{E} 1$, increase when the variability increase in the domain of measurement and when at the same time non-linear relations exist between the investigated variables and the radiances. Concerning the estimation of $L E$ and $A_{c}$ in our conditions, some of the factors that affect error values are described below, as well as a partial explanation of some of them.

- Differences exist between $L E$ and $A_{c}$ because these variables do not always have the same behaviour depending on the land use. Bare soils have evaporation but not photosynthesis. As simulated scenes often include bare soils, the variability of $A_{c}$ may be larger than the variability of $L E$ (this may explain the larger errors E2 for $A_{c}$ than for $L E$ ).

- Both $A_{c}$ and $L E$ increase for each canopy cover, while surface temperatures decrease, when water availability increases. States 1 and 4 are quite homogeneous, since all the media are in the same water conditions. They generally present lower E1 and E2 errors compared to moisture states 3 and 2 , which contain surfaces with different water conditions and then are more heterogeneous. It is also interesting to note that for a given type of canopy, many works have shown that variations in water status generate a linear relationship between the fluxes and the surface temperature (see Seguin and Itier 1983, Choudhury 1989 or Friedl 1996, for instance). In these conditions, spatialization errors are low as shown by Friedl (1996).

- Because of the large differences in aerodynamic roughness (related to vegetation height) between bare soil, low canopy (soybean or wheat) and high canopy (maize), simulated surface temperatures may be very different at a same moisture state. However, as at a same moisture state the variability in fluxes is low, errors may be still low. The effect of aerodynamic roughness was also shown by Moran et al., (1997).

An important point to assess are the differences between E2 and E3, and then the validity of the spatialized model. Errors E3 are always significantly lower than E2, showing the good performances of the spatialized model when quantifying $A_{c}$ and $L E$ over heterogeneous pixels. Also, the comparison between the errors E3 and E1 shows that the relative error of spatialization $\mathrm{E} 3$ is lower when the scene is heterogeneous. Indeed, the scene heterogeneity increases the gap $\left(R^{\wedge}-R_{\vee}\right)$ and decreases the spatialization error E3. 

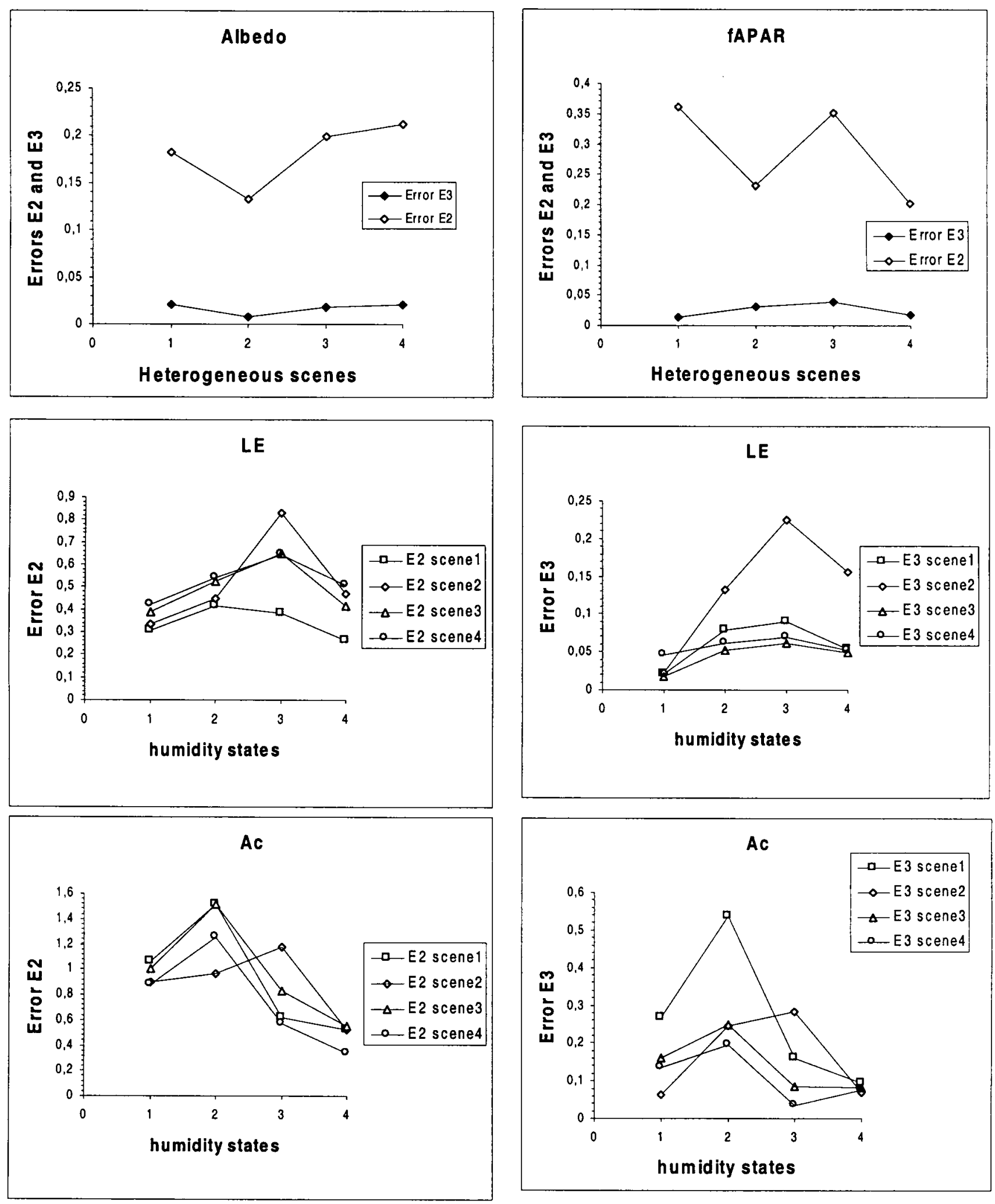

Figure 7.

Relative maximum errors (E2) and the relative errors of spatialization (E3) as a function of heterogeneous scenes. 


\section{Conclusion}

The general problem of the role of heterogeneity in remote sensing models has been dealt with in the particular case of photosynthesis, evapotranspiration, albedo and fraction of photosynthetically active radiation absorbed, and their estimation from global radiances of the pixel. We used the ALiBi SVAT model to compute these variables at local scale. This model depends on various parameters noted $p$ and representing the physiology and the geometry of plants, only measurable at the local scale, and does not allow for the computation of the variables of interest for heterogeneous areas. This is the key reason for the difficulty in using SVAT models with satellite data.

In this study, we use a new method that allows computing the maximum error of spatialization, knowing only radiance $\vec{L}(\Omega) \epsilon D$. Moreover, a spatialized model often reduces the errors due to both scaling and pixel heterogeneity. The spatial heterogeneity is strongly scaling related. We studied the scaling problem by simulating spatially heterogeneous landscapes. We also analyzed the effect of the mixture of moist media with dry media in the same landscape.

We showed that the albedo is a variable almost insensible to heterogeneity. This is because the albedo is expressed as a quasi-linear function of red and near-infrared reflectances. Indeed, linear models are not affected by the scaling problem. The $f A P A R$ also presents a small error, because the relation between the absorption efficiency and the reflectances is almost linear. However, the error due to the heterogeneity is large for the evapotranspiration $L E$ and the photosynthesis $A_{c}$. This error may exceed the actual value of the variable itself. For the same type of heterogeneous landscape, the relative error due to the heterogeneity is different between $A_{c}$ and $L E$. It shows that sensitivity to the scale problem depends on the type of model and its non-linearity. The mixture of moist media with dry media in the same scene also increases the error in the estimation of these variables. Consequently these variables are not accurately computed directly without taking into account the change of scale problem. In this situation, the spatialized model gives more accurate results: the comparison between maximum relative error due to the heterogeneity and the error of the spatialized model shows the precision of the spatialized model in the quantification of these variables.

We conclude that the spatialized model gives accurate results in the computation of latent heat flux over heterogeneous landscapes (the results are somewhat less accurate for photosynthesis). The use of this spatialization method can be generalized and can be applied to the study of diverse areas, with any levels of heterogeneity and model types. We will evaluate further the validity of this method by comparison to experimental remote sensing data in the frame of the Alpilles-ReSeDA program (Olioso et al., 1998).

\section{REFERENCES}

Asrar, G., M. Fuchs, E.T. Kanemasu and J.L. Hatfield. 1984. "Estimating Absorbed Photosynthetic Radiation and Leaf Area Index from Spectral Reflectance in Wheat". Agronomy Journal, Vol. 76, pp. 300-306.
Baret, F. and A. Olioso. 1989. "Estimation à partir des mesures de réflectance spectrale du rayonnement photynthétique actif absorbé par une culture de blé". Agronomie, Vol. 9, pp. 885-895.

Bouguerzaz, F. 1997. "Contribution à l'étude du rôle du changement d'échelle dans certains modèles de télédétection utilisant les canaux visible, proche infrarouge et infrarouge thermique". Thèse de l'Université Louis Pasteur, Strasbourg 1, 190 pages.

Calvet, J.C., J. Noilhan, and P. Bessemoulin. 1998. "Retrieving the RootZone Soil Moisture from Surface Soil Moisture or Temperature Estimates: A Feasibility Study Based on Field Measurements". Journal of Applied Meteorology, Vol. 37, pp. 371-386.

Camillo, P.J. 1991."'Using One- and Two-Layer Models for Evaporation Estimation with Remotely Sensed Data". In Land Surface Evaporation. Measurement and Parameterization, Springer-Verlag (New York), pp. 183-197.

Choudhury, B.J. 1989. "Estimating Evaporation and Carbon Assimilation Using Infrared Temperature Media: Vistas in Modelling". In Theory and Applications of Optical Remote Sensing (Asrar, G., Ed.), Wiley Interscience, pp. 629-690.

Delécolle, R., S.J. Maas, M. Guérif, and F. Baret. 1992. "Remote Sensing and Crop Production Models: Present Trends". ISPRS Journal of Photogrammetry and Remote Sensing, Vol. 47, pp. 145-161.

Duguay, C.R. and E.F. LeDrew. 1992. "Estimating Surface Reflectance and Albedo from Landsat Thematic Mapper Over Rugged Terrain". Photogrammetric Engineering Remote Sensing, Vol. 58, pp. 551-558.

Fourty, T. and F. Baret. 1996. "Vegetation Water and Dry Matter Contents Estimated from Top of the Atmosphere Reflectance Data", Remote Sensing of the Environment, Vol. 56, pp. 104-117.

Friedl, M.A. 1996. "Relationships Among Remotely Sensed Data, Surface Energy Balance, and Area-Averaged Fluxes Over Partially Vegetated Land Surfaces". Journal of Applied Meteorology, Vol. 35, pp. 2091-2103.

Gillies R.R., T.N. Carlson, J. Cui, W.P. Kustas and K.S. Humes. 1997. "Verification of the 'Triangle' Method for Obtaining Surface Soil Water Content and Energy Fluxes from Remote Measurements of the Normalized Difference Vegetation Index NDVI and Surface Radiant Temperature". International Journal of Remote Sensing, Vol. 18, pp. 3145-3166.

Goel, N.S. and D.E. Strebel. 1984. "Simple Beta Distribution Representation of Leaf Orientation in Vegetation Canopies". Agronomy Journal, Vol. 76, pp. 800-802.

Gonzalez-Dunia, J. 1995. "Le bilan hydrique dans le continuum sol-planteatmosphere: étude des processus isotopiques, micrométéorologiques et écophysiologiques". Thèse de l'Université de Paris VII, 117 pages

Hope, A.S., S.N. Goward and D.E. Petzold. 1988. "Tersail: A Numerical Model for Combined Analysis of Vegetation Canopy Bidirectional Reflectance and Thermal Emissions". Remote Sensing of Environment, Vol. 26, pp. 1-17.

Jackson, R.D. 1984. "Total Reflected Solar Radiation Calculated from Multi-Band Sensor Data”. Agricultural and Forest Meteorology, Vol. 33, pp. 163-175.

Jacquemoud, S., and F. Baret. 1990. "PROSPECT: A Model of Leaf Optical Properties”. Remote Sensing of Environment, Vol. 34, pp. 75-91.

Kreis, W. and M. Raffy. 1993. "Milieu homogène équivalent pour l'étude des flux de chaleur sol-atmosphère par télédétection". In Hiérarchies et Échelles en Écologie, Naturalia Publications, pp. 285-298.

Lynn, B. and T.N. Carlson. 1990. "A Stomatal Resistance Model Illustrating Plant Versus External Control of Transpiration". Agricultural and Forest Meteorology, Vol. 52, pp. 5-43. 
Moran, M.S., K.S. Humes and P.J. Pinter, Jr, 1997. "The Scaling Characteristics of Remotely-Sensed Variables for Sparsely-Vegetated Heterogeneous Landscapes". Journal of Hydrology, Vol. 190, pp. 337-362.

Olioso, A. 1992. "Simulations des échanges d'énergie et de masse d'un couvert végétal, dans le but de relier la transpiration et la photosynthèse aux mesures de réflectance et de température de surface". Thèse de l'Université de Montpellier II, 254 pages.

Olioso, A. 1995. "Estimating the Difference Between Brightness and Surface Temperatures for a Vegetal Canopy". Agricultural and Forest Meteorology. Vol. 72, pp. 237-242.

Olioso. A., T.N. Carlson and N. Brisson. 1996a. "Simulation of Diurnal Transpiration and Photosynthesis of a Water Stressed Soybean Crop". Agricultural and Forest Meteorology, Vol. 81. pp. 41-59.

Olioso, A., O. Taconet and M. Ben Mehrez. 1996b. "Estimation of Heat and Mass Fluxes from IR Brightness Temperature". IEEE Transactions on Geoscience and Remote Sensing, Vol. 34, pp. 1184-1190.

Olioso, A., L. Prévot, F, Baret, A. Chanzy, et al., 1998. "Spatial Aspects in the Alpilles-ReSeDA Project". In Scaling and Modelling in Forestry: Application in Remote Sensing and GIS, (Marceau, D.J., ed.). Université de Montréal, Canada, pp. 93-102.

Olioso, A., H. Chauki, D. Courault and J.-P. Wigneron. 1999a. "Estimation of Evapotranspiration and Photosynthesis by Assimilation of Remote Sensing Data into SVAT Models". Remote Sensing of Environment, Vol. 68, pp. 341-356.

Olioso, A., H. Chauki, J.-P. Wigneron, K. Bergaoui, P. Bertuzzi, A. Chanzy, P. Bessemoulin and J.-C. Calvet. 1999b. "Estimation of Energy Fluxes from Thermal Infrared, Spectral Reflectances, Microwave Data and SVAT Modeling". Physics and Chemistry of the Earth, Part B., Vol. 24, pp. 829-836.

Ottlé, C. and D. Vidal-Madjar. 1994. "Assimilation of Soil Moisture Inferred from Infrared Remote Sensing in a Hydrological Model Over the HAPEX-MOBILHY Region”. Journal of Hydrology. Vol. 158. pp. 241-264.

Raffy, M. 1992. "Change of Scale in Models of Remote Sensing: A General Method for Spatialization of Models". Remote Sensing of Environment, Vol. 40, pp. $101-112$.

Rafty, M. 1994. "Heterogeneity and Change of Scale in Models of Remote Sensing. Spatialization of Multispectral Models". International Joumal of Remote Sensing, Vol. 8, pp. 723-734.

Seguin, B. and Itier, B. 1983, "Using Midday Surface Temperature to Estimate Daily Evaporation from Satellite Thermal IR Data". International Journal of Remote Sensing, Vol. 4, pp. 371-383.

Sellers, P.J. 1985. "Canopy Reflectance, Photosynthesis and Transpiration". International Journal of Remote Sensing, Vol. 6, pp. 1335-1372.

Sellers, P.J., M.D. Heiser and F.G. Hall. 1992. "Relations Between Surface Conductance and Spectral Vegetation Indices at Intermediate $\left(100 \mathrm{~m}^{2}\right.$ to 15 $\mathrm{km}^{2}$ ) Length Scales". Joumal of Geophysical Research, Vol. 97, D17, pp. 19033-19059.

Sellers, P.J., M.D. Heiser, F.G. Hall, S.J. Goetz, D.E. Strebel, S.B. Verma, R.L. Desjardins, P.M. Schuepp and J.I. MacPherson. 1995. "Effects of Spatial Variability in Topography, Vegetation Cover and Soil Moisture on AreaAveraged Surface Fluxes: A Case Study Using the FIFE 1989 Data". Joumal of Geophysical Research, Vol. 100, D12, pp. 25607-25629.

Sellers, P.J., S.O. Los, C.J. Tucker, C.O. Justice, D.A. Dazlich, G.J. Collatz and D.A. Randall. 1996. "A Revised Land Surface Parameterization (SiB2) for Atmospheric GCMs. II. The Generation of Global Fields of Terrestrial Biophysical Parameters from Satellite Data". Journal of Climate, Vol. 9, pp. $706-735$
Soer, G.J.R., 1980. "Estimation of Regional Evapotranspiration and Soil Moisture Conditions Using Remotely Sensed Crop Surface Temperature". Remote Sensing of Enviromment, Vol. 9, pp. 27-45.

Taconet, O., R. Bernard and D. Vidal-Madjar. 1986. "Evapotranspiration Over an Agricultural Region Using a Surface Flux/Temperature Model Based on NOAA-AVHRR Data". Jommal of Climate and Applied Meteorology, Vol. 25, pp. 284-307.

Toll, D.L. 1989. "Solar Surface Estimation Using Remotely Sensed Spectral Data". In Proceedings of IGARSS'89, 10-14 July. Vancouver, Canada. Vol. 1, pp. 177-180.

Van de Griend. A.A. and J.H. Van Boxel. 1989. "Water and Surface Energy Balance Model with a Multi-Layer Canopy Representation for Remote Sensing Purposes". Water Resources Research, Vol. 25. pp. 949-971.

Verhoef, W. 1984. "Light Scattering by Leaf Layers with Application to Canopy Reflectance Modelling: The Sail Model". Remote Sensing of Environment, Vol. 16. pp. 125-141.

Verhoef W. 1985. "Earth Observation Modelling Based on Layer Scattering Matrices". Remote Sensing of Enviromment, Vol. 17, pp.165-178.

Wang, J. and E.F. LeDrew. 1989. "Derivation of Climatological Surface Albedo Over a Drainage Basin from High Resolution Airborne Data". In Proceedings of IGARSS'89, 10-14 July, Vancouver, Canada. Vol. 3, pp. 17751778 .

Winkel, T., and S. Rambal. 1990. "Stomatal Conductance of Some Grapevines Growing in the Field Under a Mediterranean Environment". Agricultural and Forest Meteorology. Vol. 51, pp. 107-122.

Wydick, J.E., P.A. Davis and A. Gruber. 1987. "Estimation of Broadband Planetary Albedo from Operational Narrowband Satellite Measurements". NOAA technical report NESDIS 27, NOAA/NESDIS Washington D. C., USA. 